\title{
INTRODUÇÃO
}

\section{PERSPECTIVAS ANALÍTICAS PARA O ESTUDO DAS INOVAÇÕES CAMPONESAS}

Aquiles Simões

Como emergem as inovações entre os camponeses? Como apoiar e colocá-las em interação com os sistemas de conhecimento instituídos quando essas já foram caracterizadas como "discretas" (ALBALADEJO, 2001), "ordinárias" (ALTER, 2000) ou mesmo "invisíveis" (SABOURIN et al., 2006)? Como saber se a inovação é endógena ou localizada, e se faz sentido para os camponeses e suas organizações, consolidá-las num sistema de conhecimento local?

Essas questões abrem esse número temático da revista e estão no cerne do debate colocado no artigo de Eric Sabourin, Pablo Sidersky, Luciano da Silveira e Henri Hocdé, que, apoiando-se na experiência concreta de grupos de camponeses experimentadores na região do Agreste da Paraíba, demonstram à luz da sociologia da inovação e da pesquisa-ação-desenvolvimento, como as relações tecidas entre os diferentes atores permitem valorizar a inovação local ou endógena, trabalhadas e socializadas pelos próprios camponeses, constituindo-se em referências regionais.

Os estudos sobre as inovações mostram que os camponeses inovam de forma individual na escala da parcela cultivada, dos rebanhos ou do sistema de produção, mas o fazem em função de interações entre si e com diversos atores e objetos no âmbito de redes (DARRÉ, 1986a, 1986b) e teias de aprendizagens (SIMÕES, 2007) sociotécnicas e coletividades locais, tais como aqueles que foram analisados, entre outros, por Callon (1986; 1991) e Assis (2001). Podemos ainda alargar essa perspectiva se considerarmos que as inovações também emergem em situações de "interface social" (LONG, 1989) criadas pelas interações entre agentes de intervenção social, os camponeses e suas organizações. $\mathrm{O}$ artigo apresentado por Luiz Eugênio Pasin, Lídia Barreto, Elisa Souza, Ana Paula Dib e João
Carlos Nordi, se constitui uma importante referência nesse sentido, ao trazer para o debate a experiência dos apicultores do Vale do Paraíba - SP.

Juntamente com o artigo de Sabourin et al., o trabalho de Pasin e seus colegas nos permite colocar o olhar crítico sobre as abordagens participativas e os processos geradores de arranjos institucionais, adaptações e invenção metodológica, a exemplo da "Ciranda do $\mathrm{Mel}^{\prime}$, que media a interação entre diversos atores e o confronto de mundos sociais distintos. Tal perspectiva nos parece pertinente à compreensão das relações entre pesquisa, pesquisa-formação, extensão rural, políticas públicas e setor privado na concepção e acompanhamento das inovações, e do papel que os agentes institucionais e camponeses podem desempenhar.

Defrontamo-nos atualmente com uma dupla constatação: a) nem todas as inovações em curso correspondem ao postulado de que sua existência se deve ao acréscimo de um novo elemento (juntar algo novo às práticas existentes), e; b) nem se devem também à reconfiguração dos elementos associados a esse "acréscimo de algo novo". Esse número da revista Agricultura Familiar se mostra como uma interessante contribuição científica acerca dos processos de inovação ao trazer à reflexão, trabalhos que demonstram que as inovações não se estruturaram somente dessa maneira.

Há, com efeito, uma tradução das práticas operada pelos próprios camponeses, no plano epistemológico e cognitivo, face às suas percepções da situação, das vantagens e restrições do meio biofísico, do campo de possibilidades aberto pelo reconhecimento da condição de "agricultor familiar", da interação com políticas públicas e com o saber especia- 
lizado. Ou seja, nos parece pertinente evocar que também se tratam de inovações e aprendizagens sociais que refletem as estratégias levadas a cabo para a reprodução do grupo doméstico, manutenção da vida associativa e emergência de novas formas de sociabilidades que preconizam a interação com a sociedade global, traduzindo no espaço social as práticas produtivas e organizativas.

Essa perspectiva é desvendada no artigo de autoria de Iara Henn e Serinei Grigolo, cuja análise socioantropológica mostra como as sementes crioulas se constroem como um símbolo através dos qual se estruturam grupos e movimentos sociais, permitindo a circulação de saberes que, por sua vez, renovam tal símbolo no espaço social em que ele se produz e se reproduz: as festas das sementes crioulas.

O trabalho apresentado por Anny Linhares e Clarissa dos Santos e realizado numa comunidade produtora de farinha no município de Mocajuba - PA, além de tratar da casa de farinha como lugar de morada e espaço de sociabilidade, nos permite também dizer que, entre camponeses com tecnologia simples, os mais "tradicionais" ou "primitivos" sistemas envolvem um conhecimento complexo de fatores ambientais e de genética vegetal (WILKEN, 1987), a exemplo das escolhas das variedades de mandioca. O sistema de produção baseado na produção de farinha é bastante dinâmico no sentido de que ele requer monitoramento constante do meio ambiente e da tecnologia, e ajustes para alcançar seus objetivos. Neste sentido, como afirmam Turner e Brush (1987), "todos os sistemas de produção são igualmente modernos, e inovação e invenção são partes inerentes de todos os sistemas de produção".

Nessa perspectiva, outro viés possível para a compreensão da emergência das inovações é o estudo das práticas dos camponeses. O estudo das práticas não pode prescindir do camponês. As técnicas, para Teissier (1979), podem ser descritas independentemente do camponês que as implementa, enquanto que as práticas são indissociáveis do operador, assim como das condições nas quais desempenha seu oficio. "A prática é finalmente a rein- venção constante da técnica na contingência da ação. No entanto, todo ato não pode ser qualificado de prática. Para sê-lo, deve existir intencionalidade do agricultor que torna possível a repetição de uma mesma prática em outro momento e em outro lugar" (ALBALADEJO, 2000). "Num lapso de tempo limitado, a permanência das estruturas de um estabelecimento agropecuário, dos referenciais técnicos do agricultor e das restrições de origem externa levam à estabilidade temporária das regras de decisão do ator considerado. A prática é simultaneamente específica de uma dada situação e regular..." (LANDAIS; DEFFONTAINES, 1988 citados por ALBALADEJO, 2000).

Estudar as práticas e suas transformações como propõe parte do artigo de Linhares e Santos, impõem aprofundar questões sobre as relações entre os sujeitos sociais e os objetos. Bourdieu (1980) mostra que qualquer representação esquemática da prática põe em evidência os limites da "lógica da prática". Só se pode entender a lógica da prática através de construções teóricas que a desconstroem.

Articular a compreensão dos saberes e práticas em torno da produção da farinha e analisar como isso se reflete nas relações sociais vividas no espaço onde ela se materializa, a casa de farinha, é uma árdua tarefa do ponto de visto científico, exigindo esforço interdisciplinar no sentido da interação entre ciência agronômica e ciências sociais. É isso que constitui a originalidade do artigo de Anny Linhares e Clarissa dos Santos.

Na região do Baixo Tocantins, estado do Pará, o padrão de exploração baseado no extrativismo do açaí e da pesca e no desmatamento para a retirada da madeira e implantação de roças de mandioca, arroz, milho e feijão, predominante na região, vem paulatinamente sendo adaptado incluindo outras formas de exploração, que têm surgidas como experiências relevantes, na perspectiva do melhor uso, manejo e gestão dos recursos naturais, traduzindo o interesse dos camponeses à busca da sustentabilidade dos agroecossistemas ilha, várzea e terra firme.

$\mathrm{O}$ artigo de autoria de Paulo Martins, 
Moacir Pereira, Francinaldo de Matos, Bruno da Silva Júnior e Andreia Scalabrin, com ênfase à terra firme, mostra que tendo em vista as condições disponíveis do meio natural e socioeconômico, os camponeses dessa região têm se permitido, e por vezes até sido pressionados, a experimentar algumas novidades em seus estabelecimentos, tais como: manejo dos açaizais nativos e cultivo do açaí em zonas de terra firme, a introdução de novos tipos de pequenas criações (como peixes e abelhas), além do cultivo de espécies perenes, principalmente espécies frutíferas e de reflorestamento, implantação de sistemas agroflorestais, manejo da diversidade nos quintais agroflorestais e desenvolvimento de experiências de gestão da fertilidade do meio natural, a exemplo da proteção do solo com a "palhada" dos cultivos. Essas transformações se inscrevem num processo caracterizado de "inovação agroecológica" e contam com a mediação de ONGs de apoio ao desenvolvimento como é o caso da APACC (Associação de Apoio às Comunidades Carentes).

Ao lado dessas experiências emergem também inovações institucionais para a regulação, uso e gestão dos recursos pesqueiros, a exemplo dos acordos de pesca na região das ilhas, sobretudo em comunidades situadas à jusante da barragem de Tucuruí e que foram diretamente atingidas pela mudança na vazão do rio Tocantins. $\mathrm{O}$ artigo apresentado sobre a comunidade de Pacuí de Baixo, no município de Cametá, por Francinei Tavares e Sara Dias, se constitui então numa fértil reflexão, à luz da sociologia da tradução e da análise de conflitos, acerca de como através de processos organizacionais os pescadores instituem práticas transformadoras de gestão e ordenamento da pesca que contribuem à recomposição dos seus modos de reprodução social e econômica. Além dos 6 (seis) artigos apresentados acima, esse número traz o relato de uma experiência desenvolvida na zona costeira do estado de Santa Catarina, e um ensaio etnográfico focado nos efeitos socioambientais associados à implementação de grandes projetos de desenvolvimento, como é o caso das barragens para a produção de energia.
A experiência desenvolvida em Santa Catarina se apoia na concepção do "Desenvolvimento Territorial Rural com Identidade Cultural". Sergio Pinheiro, Mauro Simões, José Farias, Sandro Schlindwein e Caroline Schio, nos revelam como tal experiência se concretiza como estratégia de valorização das comunidades tradicionais, desencadeando processos pautados na aplicação dos princípios da pesquisa-ação e da Soft System Methodology que promovem à emergência de sistemas sociotécnicos e produtivos alternativos.

O ensaio etnográfico que finaliza a Revista Agricultar Familiar no 10 não se refere propriamente ao estudo das inovações camponesas do ponto de vista técnico-agronômico, econômico ou sócio-organizacional. Porém, ao fazer uso da fotoetnografia (antropologia visual), da memória oral e da escrita camponesa, os autores Matheus Benassuly, Aquiles Simões, Sônia Magalhães e Bianca Amorim, inovam do ponto de vista metodológico no seio do grupo de pesquisa do qual fazem parte, pois findam por demonstrar como essa forma de produzir conhecimentos sobre as sociedades camponesas permite desvendar, compreender e refletir, em última análise, sobre os conflitos socioambientais inerentes a construção de barragens, a exemplo de Tucuruí e Belo Monte, e suas implicações sobre o modo de vida camponesa.

Para concluir essa introdução é importante lembrar que Geertz (1983) nos ensina que o conhecimento, o pensamento, é social e historicamente construído, sendo em si um ato público: "pensamento humano é social do começo até o fim: social nas suas origens, social nas suas funções, nas suas formas e nas suas aplicações. Finalmente, pensar é uma atividade pública: pensa-se naturalmente no âmbito familiar, nos mercados ou na praça do povoado". Nessa concepção, é a atividade, principalmente a atividade social que faz o saber, que produz processos de inovação.

Assim sendo, os artigos aqui apresentados nesse número temático sobre os processos de inovação camponesa, nos levam a duas consequências metodológicas intrinsicamente 
relacionadas no estudo das inovações como atividade social: o caráter social dos saberes dos camponeses, a completude e diversidade deles, ou seja, quem os produz e o que são.

\section{REFERÊNCIAS}

ALBALADEJO, C. O diálogo para uma interação entre os saberes dos agricultores e os saberes dos técnicos: uma utopia necessária. In: HÉBETTE, J., NAVEGANTES, R. da S. (Org.). CAT - Ano Décimo: etnografia de uma utopia. Belém: Edufpa, 2000. p. 173-214.

ALBALADEJO, C. Una Argentina "discreta"...: la integración social y territorial de las innovaciones de los agricultores familiares en el partido de Saavedra (Pigüé), Argentina. Revista Universitaria de Geografia. v. 10, n 1/2, p. 131-148, 2001.

ALTER N. L'innovation ordinaire. Paris: PUF, 2000, 278p

ASSIS, W. S. de. Organizações sociais locais e o processo de inovações no caso da agricultura familiar na Amazônia. Dissertação de Mestrado. Belém: UFPA/NEAF/MAFDS, 2011. 165f. Dissertação (Mestrado em Agriculturas Familiares e Desenvolvimento Sustentável) - Universidade Federal do Pará. Centro Agropecuário. Belém, 2001

BOURDIEU, P. Le sens pratique. Paris: Éditions de Minuit, 1980.

CALLON, M. Éléments pour une sociologie de la traduction. La domestication des coquilles Saint-Jacques et des marins-pêcheurs dans la baie de Saint-Brieuc. L'Année sociologique, v.36, p. 169-208, 1986.

CALLON, M. Réseaux technico-économiques et irréversibilités. In : In : BOYER, B., CHAVANCE, B. GODARD, O.(ed) Les figures de l'irréversibilité en économie. Paris: EHESS, 1991, p.195-232
DARRÉ J.P. La production de connaissances dans les groupes locaux des agriculteurs, Agriscope, n. 7, p.24-35, 1986a.

DARRÉ, J.P. Comment les façons de faire et de penser se transforment: l'étude des réseaux de dialogue, Agriscope, n.7, p.143151, 1986.

GEERTZ, C. Bali. Interprétation d'une culture. Paris: Gallimard, 1983

LONG, N. (ed.) Encounters at the interface: a perspective in social discontinuities in rural development. Wageningen Studies in Sociology 27. Wageningen: Agricultural University, 1989

SABOURIN E, HOCDE H, TONNEAU JP, SIDERSKY. P Production d'innovations et interactions agronomes/agriculteurs dans l'Agreste de la Paraíba, Brésil. In: CANEILL, Jacques. Agronomes et Innovations : 3ème édition des entretiens du Pradel. Paris:

L'Harmattan. 2006

SIMÕES, A. La réforme agraire en Amazonie brésilienne: innovation et apprentissage social. 2007, 444 p. Thèse (Docteur em Études Rurales) - Universidade de Toulouse le Mirail / Institut de la Recherche pour le Développement, 2007

TEISSIER, J. H. Relations entre techinques et pratiques. Dijon: INRAP, 1979. (. Bulletin de l'INRAP)

TURNER, Billie Lee, BRUSH, Stephen B. Comparative Farming Systems. Front Cover, Guilford Press, 1987 - Science - 428 pages.

WILKEN, G. C. Good farmers: Traditional Agricultural Resource Management in Mexico and Central America. Berkeley: University of California Press, 1987. 297 p 
ARTIGOS

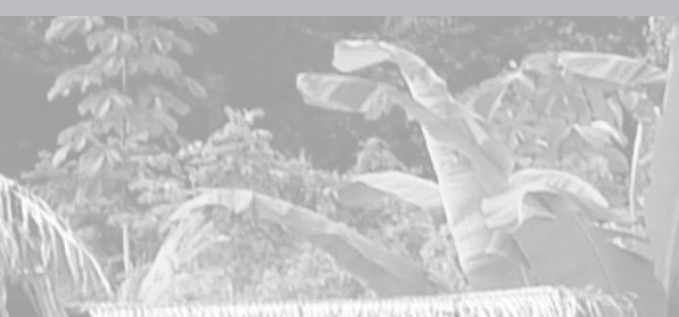

(1)

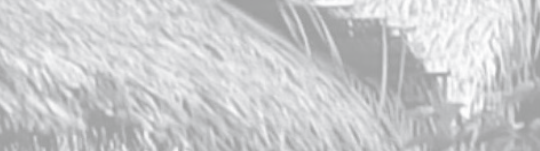

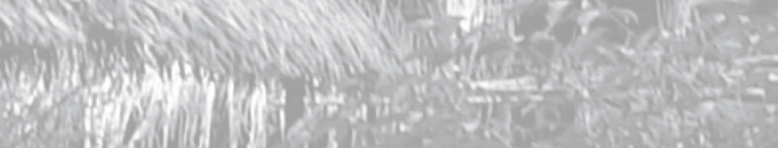

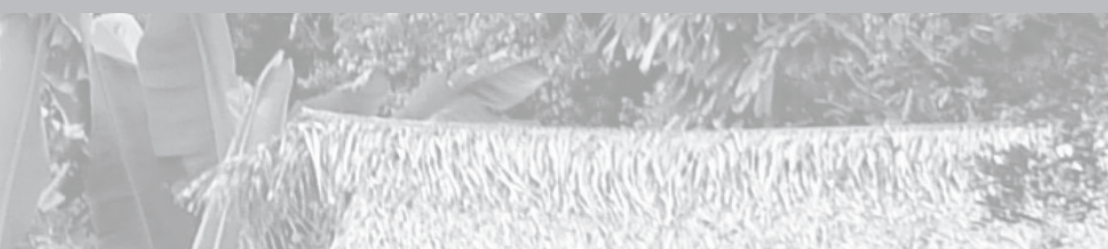
(20)
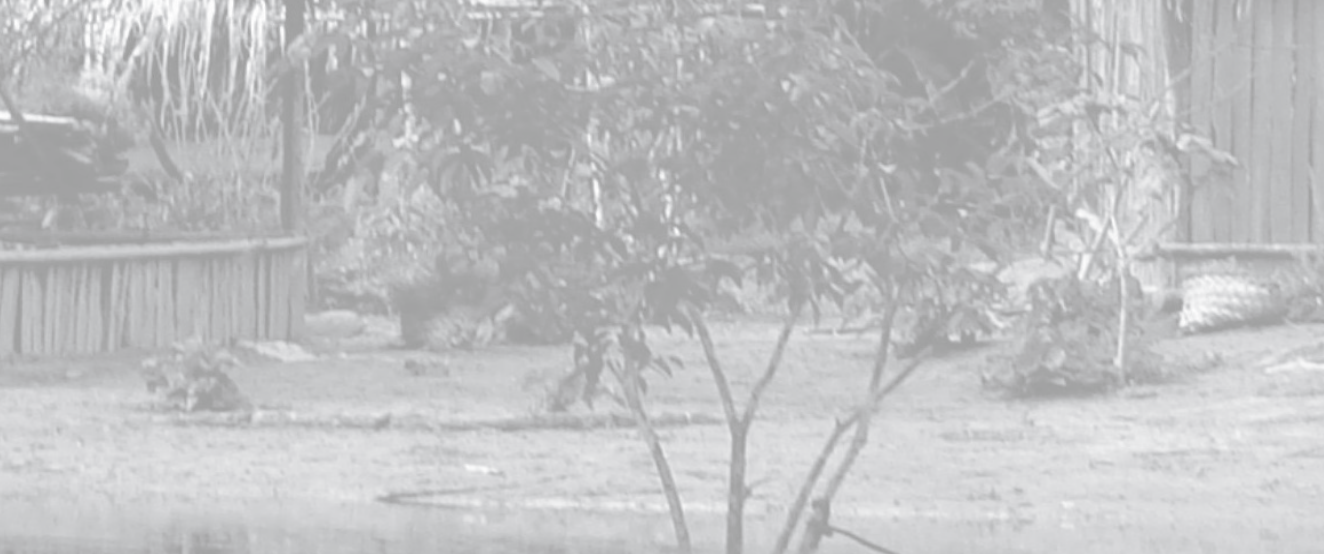
